\title{
Harnessing the Complexity of Children's Consumer Culture
}

\author{
STEVEN K. KHAN \\ Queen's University (Canada)
}

\begin{abstract}
In this paper I argue that consumption is a common matrix of childhood experience that children bring to curriculum, schooling and learning. Next I describe how children's consumer culture (CCC) can be seen to share some important characteristics of complex systems. Finally, I address the question of how the emergent potential of children's consumer culture could be utilized by educators to assist in the project of forming lifelong ethical relationships with and between peoples, places, things, and thoughts. Unprecedented changes on a global scale have revealed our traditional notions of citizenship as being deficient, partial, and incomplete. These changes prompt us, then, to examine what it might mean to be a citizen in a truly globalized and technologically connected world. Schools and curriculum have an important role to play in an unfolding political project to craft new social, natural, cultural and ethical contracts. The context through which such a project could emerge, I suggest, is from within the complex system that is children's commercial culture. Neither school and its curriculum nor CCC and its curriculum by themselves have served as effective sites for a successful pedagogy of citizenship. However, both reveal only partial aspects of different cultures of power necessary for citizenship. Both powers exist in a schizophrenic tension. The space created between such tensions might be appropriated to foster a pedagogy for citizenship that emerges from a common curriculum of consumption. A complex systems perspective opens windows of possibilities that might offer a view of how such tensions could be harnessed for this project.
\end{abstract}




\section{Introduction}

Since my arrival in Canada I have been experiencing two educations; consuming two discourses. One occurs in the formal spaces of the academy, the familiar classrooms, students, textbooks, lectures, discussions, papers and presentations. The other's pedagogical propaganda arrives religiously, innocuously, every Friday in my mailbox-the Flyer Pack. Everything I 'need' to know is there in front of me in full color and vivid detail-who has what I didn't know I needed at a price I didn't know I could afford at a place I didn't know existed but only for a time that I didn't know I could spare. Both are preparing me for a life after graduate education, one to form a lifelong relationship with thoughts, the other to form a lifelong relationship with things. But the question motivating the exploration in this paper is do either adequately prepare me to engage in a process of forming a lifelong relationships with distant and diverse peoples or places?

In this paper I will attempt to argue that consumption is a common matrix of childhood experience that children bring to curriculum, schooling and learning. Next I will attempt to describe how children's consumer culture can be seen to share some important characteristics of complex systems. Finally, I hope to address the question of how the emergent potential of children's consumer culture could be utilized by educators to assist in the project of forming lifelong ethical relationships with and between peoples, places, things, and thoughts.

\section{Consumption}

In this paper I take consumption to be a dialogical relationship between two entities, the consumer and the consumed. Consumption might be viewed as a response to the 'voice' of the consumed. It is, as Schor (2004) argues, necessary to begin to view consumption as social and not merely an individual act. My intent here is to move beyond the view of consumption as eating, wasting, or using up to the broader sense of 'taking in'. I choose to use this perspective as I believe that assessments of children's consumption based solely on capital expenditure, though gargantuan, grossly underestimate the true 'value' of children's consumption. Furthermore, this expanded definition provides the conceptual space necessary for me to imagine the potentials of harnessing this phenomenon, thus moving it beyond the emotional rhetoric of moral panics (Cook, 2001).

Consumption is interwoven with the formation of an identity. As Martens, Southerton and Scott (2004) state, "... through consumption individuals have greater capacity to decide 'who they want to be' and narrate their identity by appropriating styles of consumption..." (p. 15). McNeal (1992, cited in Linn, 2004) states that, "Kids are the most unsophisticated 
of all consumers; they have the least and therefore want the most" (p. 183). This may be the result of Schor's (2004) suggestion that they are the most "emotionally vulnerable" (p. 65) consumer population. The nature of the experience of childhood, as one of ongoing and unfolding identity formation through a continuous taking in and desire to take in, suggests that we might view the basic identity of children as that of consumer. My next question then is, in the polyphony of voices 'taken in' by children, whose voice do they respond to in the construction of their consumer identity?

\section{What is children's consumer culture?}

No one can tell you what the matrix is. You have to see it for yourself. (Wachowski \& Wachowski, 1999)

Children's consumer culture (CCC) is more than what children buy or what is bought on behalf of them. It is what they take in. It is what they come to desire. It is the identity that is constructed for and by them. It is my belief though that corporate culture, through commercial culture, has coopted popular culture for the political and pedagogical task of creating and maintaining a culture of consumption among children. This culture initiates children into patterns of consumption, of taking in, which distorts their basic consumer identity. In the increasingly urbanized and sub-urbanized, postmodern, Western capitalist democracies the identity of, "being a good citizen [increasingly] means being a good consumer" (Reynolds, 2004, p. 21).

What is the difference between corporate culture, commercial culture, consumer culture, and popular culture? According to Giroux (2000a, cited in Reynolds, 2004) corporate culture refers to an "ensemble of ideological and institutional forces that functions politically and pedagogically to ... produce compliant workers, depoliticized consumers, [and] passive citizens (p. 41)" (p. 21). This idea is taken up by Reynolds (2004) who argues that we are living in a 'brand-name' corporate order and that "the construction of identity through brands is the manner in which corporations are beginning to operate" (p. 23). Langer (2004) suggests that "the intimate entangling of brand and identity is nowhere more evident than in the experience of childhood in the last two decades of the $20^{\text {th }}$ century" (p. 263). According to Hall (1992, cited in Giroux, 2000), "Everybody now inhabits the popular, whether they like it or not" (p. 163). Similarly, Linn (2004) states, "The culture of marketing that pervades all our communities, from the poorest to the richest, is similar..." (p. 32), or as Reynolds (2004) puts it, "... we live in the present historical conjuncture that is corporatized, and our cathedrals of spiritual fulfillment are the shopping malls" (p. 20). Thus, the corporate, the spiritual, the political and the pedagogical become caught up in the pervasive matrix, the maelstrom that is popular (read corporate, 
read consumer, read commercial) culture. If there exists any criterion that unites children at this point and place in history I would say it is their consumption of (and by) this culture.

Thus, I will use CCC to refer to the culture engendered by the taking in of corporate / commercial / popular products and ideology and reserve children's consumption for the more general 'taking in' as defined previously.

\section{Patterns of Consumption: Where, When and How is CCC Learnt?}

Langer (2004) describes childhood as, "a key moment in the social formation of global consumers, and children a major target market for global capital" (p. 253). Linn (2004) in Consuming Kids, describes how marketing to children seeks to create 'cradle to the grave' brand loyalty. Her argument that "every aspect of children's lives ... is negatively affected by their involuntary status as consumers in the marketplace" (p. 1) is strengthened by an overwhelming volume of empirical evidence and examples. These include insider reports of marketing industry practices, examples of marketing to babies, the marketing of play, food marketing, the use of sex in advertising, alcohol and tobacco marketing to children, marketing in schools, the marketing of violence and the marketing of values. Her description of this environment as a "marketing maelstrom" is apt as one feels disoriented and sick as case after case is described.

For example, Linn (2004) discusses how marketers have utilized parental insecurities, guilt and hectic lifestyles to create an 'under-two' market for children's 'edutainment'. She claims that interaction with these 'commoditoys' (Langer, 2004) does not provide any greater benefit than talking to and playing with a child This though is part of a larger strategy that later targets older children's need to be in control (affectionately called the 'nag factor' or 'pester power'). She writes, "By encouraging children to nag, and by bombarding them with messages that material goods are the key to happiness, the marketing industry is taking advantage of parents' innate desire for their children to be happy" (Linn, 2004, p. 39) and, for many parents, their inability to devote a lot of time arguing with their children. As children get older the marketing strategies adapt to take advantage of their "developmental vulnerabilities" (p. 24). She discusses the creation of the 'tween' marketing niche (six to eleven year olds) as an example where developmentally diverse groups of children are categorized together and products marketed to them with potentially adverse psychological effects. Linn's (2004) exposition is complemented by Schor's (2004) findings using structural equation modeling that provide strong support that "[h]igh consumer involvement is a significant cause of depression, anxiety, low self-esteem and psychosomatic complaints" (p. 167) among (American) 
children. Schools in some instances have become accomplices in this business of enculturating kids into (corporate) patterns of consumption. The trend continues with older kids being targets for marketing that takes advantage of their desires for autonomy and empowerment. Increasingly, it is argued, brands are re-positioning themselves as not only aids to living but as routes to meaning and spiritual fulfillment (Reynolds, 2004).

According to Langer (2004) the estimated independent spending power of elementary age children in the USA was around 15 billion dollars per year in 2000 and children influenced the spending of another 160 billion dollars. Furthermore, he states that "children's global contribution to corporate profit through the purchase of food, drink, licensed clothing, sneakers, sports equipment, computers, movies, and theme park attendance [is] currently estimated at more than $\$ 450$ billion" (p. 256). This is a lucrative market.

Children's consumer culture is a product of children's basic nature as consumers. Corporate culture has capitalized on this to imprint and condition children into patterns of consumption that mimic positive feedback mechanisms. The most powerful lesson that may be learnt from children's popular culture by children may be how to be a 'good' (corporate) consumer! It is unlikely that adults can prevent children from consuming popular culture, given that all of us are enmeshed in this matrix and that adults serve as the doorway to consumer culture. Thus, the corporate entity that produces popular culture becomes a pedagogue to whose voice we cannot help but pay attention (Cook, 2001). However, the unfettered hydra of commercial culture as the main site of children's identity formation is problematic as it distorts the relationship between their role as consumers and potential role as citizens.

Children begin to learn consumer culture from the moment that they are wrapped in their blanket covered with licensed cartoon characters. It is a culture that they continue to consume as they traverse the pedagogical spaces of home, school, playground, and the mall into adult life.

\section{Curricula Concerns about CCC?}

...nowadays, most schools are not producing critically reflective democratic citizens; they are far more engaged in the mass production of idiocy. I use this phrase with precision: the ancient Greek etymology of idios refers to a 'purely private person,' one who could participate in the polis as a citizen, but did not. (Burch, 2000, p.197)

A number of authors raise concerns about children's consumer culture. I will briefly examine some of this literature under the headings of: 'What are children learning?' 'What aren't children learning?' and 'Who is doing the teaching?' 
What are Children Learning From Their Engagement with Consumer Culture?

Surely something is learnt when one encounters and engages with the stories, characters and activities sold by popular culture industries ... popular characters, images and stories encode premises about ways of acting in the world, about what is good or right, about the appropriate consequences for one's actions and so on. (Cook, 2001, p. 83)

If learning is taken to be a "disposition to dialogue", as described by Visser (2001), then we might ask what types of dispositions are children developing from their dialogue with consumer culture? Linn (2004) describes several of these dispositions and some of the potential consequences. In looking at the market for children's toys she suggests that one message for children is that "whatever they generate is not good enough" (p. 64) and suggests that such a message promotes conformity, impulsivity, and defining self-worth and happiness by what one owns; all characteristics of good (corporate) consumers. In examining food marketing in the light of childhood obesity, juvenile onset diabetes and conditions such as anorexia nervosa and bulimia, she discusses the way in which food has become associated with self-determination and concludes that, "the conception of food as empowerment may be the most dangerous ways the food industry exploits children's vulnerabilities ..." (p. 102). Also addressed are the desensitizing and potentially life-threatening lessons transmitted about sex, violence, and drug use (alcohol and tobacco) as these relate to adult concerns of promiscuity, bullying and addictive behaviors. Ultimately, though, the lessons learned from consumer culture are lessons about values.

Children's consumer culture is not value-neutral as many of its purveyors would have us believe. Some of the values marketed to children include materialism, that things make you happy; dispositionism, that our choices arise from who we are and are not influenced by our environment; and unexamined brand loyalty (Linn, 2004). Langer (2004) argues that anomy or perpetual dissatisfaction is the essential state induced by CCC as consumers seek stimulation rather than satisfaction from products. He states, "Their essential feature is that satiation is endlessly postponed. Each act of consumption is a beginning rather than an end ..." (p. 255). One needs only think of the infinite accessorisation, incremental upgrades and inevitable announcement of 'one more thing' that accompanies many 'must have' consumer purchases today or the number of branded product tieins to popular movies, television shows and music that helps children to deepen their relationship and identification with brand values.

Other concerns about values learnt from children's corporate/ popular culture have ignited 'moral panics' among adults (Cook, 2001) which are 
inflated and stereotypical fears that one group has about another group's behaviors which they often cast as deviant, subversive or dangerous (Cohen, 1972; Schor, 2004). These fears include the promotion of selfishness, greed, anti-religious, anti-establishment, anti-adult messages and addictive behaviors such as gambling. Traditional pedagogical sites are not impervious to this curriculum of CCC. Reynolds (2004) discusses the increasing irrelevance and insignificance to children of discrete prepackaged knowledge that is learnt in school. It is, he describes, "only something to be suffered through, memorized, recalled and promptly forgotten on the way to the real currency of the postindustrial, global, corporate order ... popular culture" (p. 25).

Children's consumption is intimately linked to their identity formation (Giroux, 2000, Martens et al., 2004). Cook (2001) suggests that some marketing strategies in children's popular culture, "encourage a form of training, a way of being, that is incompatible with notions of sacred, innocent, children, but is highly compatible with aggressive, competitive capitalism" (p. 95). According to Martens et al. (2004), "learning to consume also holds implications for the social construction of consumption and the consumer...the contemporary consumer has come to take on many of the ideological roles fulfilled by the citizen" (p. 14). In CCC children are developing an identity, learning a "culture of power" (Delpit, 1988) that they need to function in the pedagogical space of consumer culture as consumers of culture. However, what they aren't learning about this culture of power is also important.

\section{What aren't Children Learning from Consumer Culture?}

One of the major concerns about CCC is that children are not learning the skills deemed necessary for full participation as citizens in a democracy. Indeed some authors view $\mathrm{CCC}$ as undermining the very foundations of western democracy. According to Linn (2004), "A government ... requires a population characterized by ... the capacity for critical thinking, cooperation, generosity, and nonviolent conflict resolution" (p. 190). Unexamined brand loyalty is equated by Linn (2004) with partisan loyalties, impulse buying with superficiality in political candidates and passivity is seen as being promoted through the reliance of children on products or magical beings to solve their problems. All of these, she argues, better serve dictatorial forms of government. Giroux (2000) similarly argues that as market forces continue to invade recreational spaces there exists fewer and fewer opportunities for children to construct "non-market based democratic identities" (p. 11) and notes that "the market approach to schooling ... contains no special consideration for the vocabulary of ethics and values" (p. 98). For many 
children in North America, democracy seems to be increasingly defined as the freedom to consume.

The global division of labor which sees a schism between design, manufacturing, marketing and consumption exacerbates the problem of uncoupling the production of commodities from the social relations and responsibilities that link producers and consumers (Langer, 2004). This potentially serves to absolve consumers of ethical, moral, and political responsibilities towards those to whom they are linked. These include factory workers, some of whom are probably children, in developing countries. This contradiction, as Langer (2004) notes, is "... only sustainable if conditions of production...remain hidden from consumers" (p. 262). This can be extended to the abjuring of responsibilities to the places where things are produced; an ecological disjunction. Thus, children fail to learn about the way in which the products and commodities they consume are produced and their possible social responsibilities to the people and places to whom they are linked.

\section{Who is Teaching our Children?}

It is time to realize that the true tutors of our children are not school teachers or university professors but filmmakers, advertising executives and pop-culture purveyors .... MTV trumps MIT. (Barber, 1996, p. 12, cited in Reynolds 2004, p. 25)

The ability to critically consider a diversity of viewpoints is essential to a healthy democratic citizenry. Media-consolidation which sees four corporations, Viacom, Disney, Time-Warner and Fox, controlling most of what children consume as popular culture is perceived as limiting the potential diversity of views to which children are exposed. As Linn (2004) notes, "Even if we can choose among a hundred television stations, how much diversity of viewpoint do we have of each of the channels is owned by one of five corporations?" (p. 176). Oligopolies exist not only in media but in the food, fashion, and toy culture industries that market to children. Such oligopolies potentially define and limit what is constructed as popular culture.

The sites of criticism within children's (or more appropriately youth) popular culture have also become corporatized. Popular music as a site of critique is a frequently cited example (Hayes \& Johnson, 2003; Reynolds, 2004). According to Reynolds (2004), “The corporate order's (read capitalism's) technique for removing any critique possibilities from artistic creations is to turn them into commodities, thereby co-opting them. Any creation potentially critical is made to be harmless, and another profit making apparatus" (p. 24). Thus while anti-establishment might be popular, there seem to be fewer popular anti-corporate criticisms. 


\section{Critique}

In the previous section I identified some of the concerns that have been raised about children's consumer/popular culture. These concerns stem from a constructed view of childhood as a sanctuary from the concerns of the adult world (Cook, 2001; Giroux, 2000). Such a view requires adults to police and protect the sanctity of childhood activities. Such a view also posits children as needing protection rather than guidance and places adults in a position of power and privilege. However as Giroux (2000) points out, "...popular culture is not only a site of enormous contradiction but also a site of negotiation for kids, one of the few spaces where they can speak for themselves, produce alternative spheres, and represent their own interests..." (p. 13). As Cook (2001) states, "Popular amusements are seen as posing a threat to contemporary childhood precisely because they are popular ..." (p. 81). Thus,

[r]ather than acknowledge that the new electronic technologies allow kids to immerse themselves in profoundly important forms of social communication, produce a range of creative expressions, and exhibit forms of agency that are both pleasurable and empowering, adults profoundly mistrust these new technologies .... (Giroux, 2000, p. 13)

This schizophrenic tension surrounding CCC and its curriculum suggests a potential avenue for pedagogical intervention.

Consider, however, the criticisms leveled against CCC: the transmission of unacceptable values; promotion of socially unacceptable or dangerous behaviors; the formation of consumer identities at the expense of the citizen identity; and the 'oligologic' nature of the corporate discourse. Are these much different from the criticisms leveled against schools and curriculum? Are not schools also complicit in the reproduction of unhealthy values and social inequalities? (Anyon, 1980). Are schools qualitatively much better at preparation for democratic citizenship than consumer culture? How much variety is there in a curriculum driven by the market like forces of accountability and profitability engendered by the "perpetual pedagogy of surveillance" (Reynolds, 2004, p. 22) of testing, reform and standards? School and its curriculum also exist in a schizophrenic tension between the political need to produce citizens and workers and the economic engine that drives modern societies through an incessant consumption (taking in).

Neither school and its curriculum nor CCC and its curriculum by themselves have served as effective sites for a successful pedagogy of citizenship. However, both reveal only partial aspects of different cultures of power necessary for citizenship. Further, "to act as if power does not exist is to ensure that the power status quo remains the same" (Delpit, 1988, p. 292). Both powers exist in a schizophrenic tension. The space 
created between such tensions might be appropriated to foster a pedagogy for citizenship that emerges from a common curriculum of consumption. A complex systems perspective opens windows of possibilities that might offer a view of how such tensions could be harnessed for this project.

\section{A Complex Systems Perspective}

The complex systems world is a world of avalanches, of founder effects, of self-restoring patterns. It is a world of punctuated equilibria and butterfly effects. It is a world where change can keep recurring in a fixed pattern, where rapid and irreversible change can occur when a certain threshold of effect is reached, where great variety can exist at a large scale, even though small patches have little variety (Axelrod \& Cohen, 1999, p. 14)

There is no simple definition of a complex system. This is partly because complexity science is "defined more in terms of its objects of study than its modes of investigation" (Davis, 2004, p. 150). These objects of study range from cells to ecosystems (biological systems), sandhills to galaxies (physical systems), computer networks/algorithms to neural networks/algorithms (cybernetic systems) and classrooms to cultures (social systems). In all of these, interactions between the many parts influence the probabilities of the occurrence or nonoccurrence of later events and thus deterministic prediction becomes unreliable. Many of these systems exhibit emergent properties, i.e. properties that belong to the system as a whole but not to individual agents. These emergent phenomena, such as consciousness for example, arise through the collective interactions of the agents. They are an example of self-organization.

Axelrod and Cohen (1999) provide a framework for harnessing complexity. In this framework they view complex systems in general as consisting of

Agents of a variety of types, us[ing] their strategies, in patterned interaction with each other and with artifacts. Performance measures on the resulting events drive the selection of agents and / or strategies through processes of error-prone copying and recombination, thus changing the frequencies of the types within the system (p. 154).

By harnessing complexity the authors imply, "deliberately changing the structure of a system in order to increase some measure of performance and to do so by exploiting an understanding that the system is complex. The idea is to use our knowledge of complexity to do better" (p. 8).

\section{Why use a Complex Systems Perspective?}

To do better! In order to move beyond the morally relativistic adage 'to do good' there is the need to recognize that the task is always incomplete, always beginning, and always in reference to some standard whose exact 
position may be impossible to pin down. 'To do better' is a powerful openended rationale for schooling in the twenty-first century as it struggles to rediscover its relevance in the "brand-name corporate order" (Reynolds, 2004). It is, as Reynolds (2004) suggests, "a working from the middle spaces ... potential without guarantees ... always remembering that the confrontation is continually tactical not strategic" (p. 31).

Reynolds (2004) argues for working from the 'in-between' to "develop new lines of flight ... that allow, however, contingently, briefly, or momentarily for us to soar vertically ... or slither horizontally ... weaving our way amid the constant reconfigurations, co-optations, and movements of the brand name corporate order" (p. 31). His vision is grounded in Deluze's (1995) philosophy of multiplicities in which the conjunction AND is given priority over the verb 'to be',

AND is neither one thing nor the other, it's always in between two things, it's the borderline, there's always a border, a line of flight or flow, only we don't see it, because it is the least perceptible of things. And yet it's along this line of flight that things come to pass, becomings evolve, revolutions take shape. (Deluze, 1995, p. 45)

These metaphors fit well within a complexivist frame whereemergencebecoming - takes place on boundaries between seeming randomness and observable structural coherence. Deluze (1995) also describes reading as "a flow meeting other flows" (p. 9). In 'reading' between the lines of popular culture and school is it possible to alter the natures and likelihoods of these flows' interactions? What might come from such interactions?

The legacies of the Industrial Revolution, its machine and factory based metaphors, emphases on predictability, control, efficiency, topdown hierarchies, impersonality, environmental cost and its static nature in dynamic circumstances, are becoming more and more anachronistic (Axelrod \& Cohen, 1999). This is especially true in educational systems. It is suggested that from a complex systems perspective it is likely that "people will be more comfortable with the ideas of perpetual novelty, adaptation as a function of entire populations, the value of variety and experimentation, and the potential of decentralized and overlapping authority" (Axelrod \& Cohen 1999, p. 29). This is what children's commercial/popular culture already offers children- novelty, adaptation, variety, freedom to experiment and a sense of shared authority. But this is not enough.

Attention is drawn to three processes as being central to harnessing complexity. These are variation, interaction, and selection (Axelrod \& Cohen, 1999), which must also be a part of the system. If CCC is to be harnessed using the framework of Axelrod and Cohen (1999) then it must first be demonstrated that CCC is in fact a complex system. This is the task to which I turn in the next section. 


\section{In what ways is CCC a Complex System?}

Davis and Simmt (2003) identify five necessary but insufficient conditions for the emergence of complex systems. These are internal diversity, redundancy, decentralized control, organized randomness and neighbor interactions. Diversity, redundancy and organized randomness are dimensions of variation in the Axelrod and Cohen framework, neighbor interactions are contained within the interactions criterion and decentralized control is one type of selection strategy. Thus I will use the framework of Axelrod and Cohen (1999) which is consistent with the Davis and Simmt (2003) framework to illustrate in what ways CCC might be considered a complex system.

\section{Variation in CCC}

Variety of agents and types is essential to providing the raw material for adaptive phenomenon to emerge. However this variety must be balanced by a level of uniformity (redundancy) that allows (meaningful) interactions between agents and types. Axelrod and Cohen (1999) suggest that a basic assumption for harnessing complexity is that "there is variety within a population that could matter" [my italics] (p. 33). The characteristics of agents and the determination of which characteristics matter, "is partly a function of which goals are being pursued" (Axelrod \& Cohen, 1999, p.34) by the population. In many complex systems, agents' actions are conditional upon the detectable actions of other agents, thus resulting in "consequences that are not smoothly proportional to causes" (Axelrod \& Cohen, 1999, p. 35).

The agents in CCC are primarily children and marketers. These occur in a variety of types. Other agents include parents, teachers, and manufacturers. The artifacts utilized by these agents include the objects, images, and sounds to which they respond and interact (consume). Despite the concentration of media ownership and marketing power, children's commercial culture exhibits large variability when viewed in terms of markets: entertainment, toys, games and fashion, to name a few. Within each market there is diversity, redundancy and overlap. For children there is sufficient space to be an individual member of a collective. As Hall (1992, cited in Giroux, 2000) notes, "everybody now inhabits the popular...so that does create a common set of languages. To ignore the pedagogical possibilities of common languages is extremely political" (p. 163). As I have argued previously, commercial culture is a common matrix of childhood experience. This matrix provides both variety and sufficient redundancy that are conditions necessary for self-organization and emergence. Of concern though is the potentially limiting view of the identity of the child as being solely that of consumer. 


\section{Interaction}

Patterns of interaction involve an appreciation of what interacts with what, when and where. These interaction patterns, "help determine what will be successful for the agents and the system, and this in turn helps shape the dynamics of the interaction patterns themselves" (Axelrod \& Cohen, 1999, p. 63). The interaction patterns of children with popular culture are both dense and diffuse (Cook, 2001; Langer, 2004; Linn, 2004).

According to Axelrod and Cohen (1999) proximity, activation and space are important concepts in understanding how interaction 'works'. Proximity refers to the likelihood of agents interacting. Activation refers to the timing of events; when interactions take place. Finally, the movement of agents and types in physical and conceptual spaces changes their proximity and thus influences their ability to interact. As described above, children are immersed in media and marketing for perhaps most of their lives. As they mature marketing strategies move with the changes in their physical and conceptual spaces. There is dense interaction with the commercial aspects of popular culture and diffuse interaction with the political aspects. It is this latter pattern that could be engaged which, in a complex system, would recursively but non-deterministically influence the former pattern of interaction and the global system of CCC.

\section{Selection}

Selection depends on criteria judged to be important or successful and leads to increases or decreases in types. One criterion of success cited by Axelrod and Cohen (1999) is 'frequently copied'. In relation to children's consumer culture the emergence of fads represents an example of selection due to frequent copying. Selection can operate at two levels, that of agents and strategies. The latter offers the advantage of more rapid copying.

Within complex systems there can be more than one metric of success. Indeed different populations of agents may have different criteria of success and even multiple criteria of success. Essential then to harnessing CCC is an appreciation that children, educators and the purveyors of popular culture might share different and multiple criteria of success. Thus, it becomes necessary to articulate what these criteria might be.

For popular culture industries criteria of success might include profit maximization, survival of brand, and colonization of desire. For educators success is often measured in terms of learning - as the ability to accumulate, reproduce, and integrate ideas. Learning may also mean producing new products or ideas or embodying principles. Delors (2004), for example, lists learning to know, learning to do, learning to be and learning to live together as the four pillars of education defined in the 1996 UNESCO 
report of the International Commission on Education for the $21^{\text {st }}$ Century. Harris (1998, cited in Davis, 2004) suggests that children measure success by their peer relations, their ability to fit in based on their desire to belong, to be individuals in a collective. Such collectivity, Davis (2004) notes, "rarely emerges around engagements with a subject matter, but around the common and continuous project of fitting in" (p. 168). Similar sentiments are voiced by Adler and Adler (1998) in their ethnographic report of preadolescent culture and identity.

Agents within each of the three groups design and select artifacts and strategies, and engage in meaningful patterns of interactions to increase their likelihood of attaining success by whatever metric they use. The three spheres: the commercial, pedagogical and social worlds of childhood might thus be seen as interacting complex systems that might benefit from a synergistic coupling that recognizes these competing metrics used by the agents.

\section{Harnessing the Complexity of CCC}

... gotta keep moving/ there's more music to make/ keep making new shit/ produce hits to break/ the monotony ... (Eminem, 2002)

By harnessing complexity I do not mean controlling it but rather acknowledging its presence and potential for fostering ongoing adaptation. Wind and water mills for example, have been designed to harness the power of chaotic forces without being fully in control of them while leaves of all shapes, sizes and colors have evolved to harness the power of sunlight. Harnessing complexity then is recognizing the potential afforded by the processes of variation, interaction and selection and thoughtfully intervening in these processes with the aim of increasing the likelihood that certain types of phenomena might occur (emerge) while acknowledging that other phenomena may also emerge but simultaneously retaining an evolutionary flexibility to respond to these unanticipated emergent phenomena. The only guarantee offered by this perspective is that complexity exists. Harnessing complexity is not a passive embracing of complexity, which in the case of children's consumer culture as it currently exists is problematic, but an attempt to leverage the unrealized and as yet unimagined emergent potentials inherent in complex systems.

The children's popular/consumer culture industries in my opinion have successfully harnessed this complexity. They have, as Kline (1993) observed, "always paid more diligent attention than educationists to children's active imaginations and incidental cultural interests ..." (p. 18). They have designed agents, types and artifacts and adopted strategies that take advantage of the complexity of children's life worlds while 
simultaneously allowing them both to achieve success as measured on their respective metrics. They have cultivated and maintained those conditions considered by Salomon and Perkins (1998) as critical for learning by any entity in any context, namely,

the ability to construct a repertoire of new representations or behaviors based on prior experience ... the opportunity to test and select among alternative representations ... or refine or combine them ... feedback of some sort... about how well an alternative fares...information sources ... guidance through self-regulation ... an approachable but manageable level of challenge ... [and] conditions that sustain motivation .... (p. 3)

By supporting the agentive potency of children and recognizing that their "interests are always found and articulated at points determined by desire ... [and that] desire is always part of the infrastructure" (Guttari, cited in Deluze, 1995, p. 19) they have successfully harnessed these interests and channeled their desires. From this has emerged a 'branded' self-organized, system that is "recuperative of disruptions" (Reynolds, 2004, p. 30). From this system emerges a politic of desire and the potential for a citizenry of consumers whose shared ideology is (corporate) consumption. This system, though, fails to provide guidance on ethics or elicit discussions of rights, duties and responsibilities. Perhaps this is not its role.

Schools in general do not appear to have been as successful at harnessing the complexity of children's life worlds for their pedagogical project as commercial culture. Operating from a "puritanical view of interests" (Guttari, cited in Deluze, 1995, p. 19) and working on a model of childhood as a 'prototype of adulthood,' something Probyn (1996, cited in Sumara \& Davis, 1999) argues against, they have attempted to suppress the "complex ways in which desire and knowledge intertwine with experiences and identity" (Sumara \& Davis, 1999, p. 198). In this way they have failed to equip their wards with the tools necessary to challenge dominant and repressive cultures of power (Anyon, 1980; Delpit, 1988) which attempt to silence dialogues around ethics, rights, duties and responsibilities. Schools and other pedagogic sites might thus benefit from a heterotopic association with CCC as a sphere where desire is already embodied.

That complexity can be harnessed but not controlled demands that its innate unpredictability be respected. Popular culture at times fails to respect this unpredictability and it is at these sites that it becomes open to co-optation by pedagogy. Its relationship with children while profitable is inherently unstable as companies become "trapped by their own promotional rhetoric" (Langer, 2004, p. 268). Klein (2000, cited in Langer, 2004) argues that "brand image is both the source of corporate wealth and the corporate Achilles heel" (p. 263). Langer (2004) wonders, "Might the roots of anti-corporate global activism be found in the 'enchanted garden' 
of global children's culture?" (p. 270). There is thus, as Giroux (2000) describes, "... the need to begin at those intersections where people actually live their lives and where meaning is produced, assumed, and contested ..." (p. 170). For children this nexus, intersecting domains of consumption, is their social, commercial and pedagogical worlds. It is a complex site where as Giroux (2000) asserts, "Educators must become border crossers (without passports), willing to examine the multiple sites and cultural forms that young people produce in order to make their voices heard within the larger society" (p. 29). Extending this argument, educators must also be willing to cross into the alien (but uncannily familiar) territory of children's consumer culture as they examine what children produce and fail to produce there. However, to merely co-opt CCC for the 'marketing' of curriculum is for schools to assume the identity of corporate culture and reproduce its values with a potential loss of diversity. What is required is a project that allows both to contribute to something that neither alone can accomplish: an emergent goal. In the final section I suggest what such a project might be.

\section{A New Citizenship}

... push this generation of kids/ to stand and fight for the right to say something you might not like / ... (Eminem, 2002)

Not only do political projects emerge out of particular contexts, but because contexts change as the relations between culture and power shift, such projects become practical only if they remain open, partial, and incomplete (Giroux, 2000, p. 169)

Previously I have argued that neither CCC nor school has created a successful pedagogy of, and for, citizenship. I have not defined, though, what I mean by citizenship. The reason for this is that unprecedented changes on a global scale have revealed our traditional notions of citizenship as being at times dysfunctional, deficient, partial, and incomplete. These changes prompt us then to examine what it might mean to be a citizen in a truly globalized and technologically connected world (Binde, 2004). In this world where "[r]ootlessness, transitoriness, and dispossession are the fallout of globalization" (O'Sullivan, 2002, p. 9) individuals and communities may end up having longer and more meaningful relationships with brands and commodities than with places or peoples. At the same time, relations with distant social others and diverse forms of thought become more the norm (Axelrod \& Cohen, 1999; Binde, 2004). The revelation then of a pluralism of values prompts the questions of Matsuura (2004) of how do we orient ourselves among these values and how do we act ethically? In this new world the need for new conceptions of what it means to be a citizen, and 
the incumbent responsibilities of global citizenship, becomes urgent if not a matter of survival.

The need for augmented social contracts and suggestions as to possible forms and framings of such global contracts are discussed in the third section of the UNESCO publication, The Future of Values (Binde, 2004). First, Jelev (2004) discusses the need to re-evaluate the role of education for citizenship. Next, Binde (2004a) discusses the importance of a 'natural' contract as described by Michel Serres (1995, cited in Binde, 2004a), as he looks at the global war against nature and the environment. Touraine (2004) follows with an argument for a cultural contract as "... the right to participate in a global world and at the same time to be culturally specific, particular and singular" (p. 219). Finally, Morin (2004) examines the need for an ethical contract and "'anthropo-ethics, or the ethics of humankind" (p. 243). All of these considerations are vital if we are to attempt a project that is truly global in magnitude. Noddings (2005) traces similar paths as she attempts to outline some of the concerns of what it might mean to be a global citizen. She poses a provocative question for many North American educators, "Dare we ask our students to consider adopting economic moderation as a virtue?" (p. 8). If we answer affirmatively, then I suggest that one approach ought to be through the minefield that is children's consumer culture.

Schools and curriculum have an important role to play in this unfolding political project to craft new social, natural, cultural and ethical contracts. However, as Ladson-Billings (2005) laments, “... schools struggle with the notion of developing global citizens because of the limited view of citizenship that they offer students" (p. 76) and suggests that, "... we must often look beyond school in order to find opportunities for students to develop competencies for citizenship, especially global citizenship" (p. 77). The context through which such a project could emerge, I suggest, is from within the complex system that is children's commercial culture. As Katz (1997, cited in Giroux, 2000) observes, "children are at the epicenter of the information revolution, ground zero of the digital world ... they occupy a new kind of cultural space" (p. 30). Giroux (2000) points out that, "... the culture of the Internet, video games, industrial rock, computerized gladiator matches and androgynous fashions provide an important resource for kids to develop their own cultural identities and sense of social agency" (p. 23). Thus children too must play a role in the shaping of these contracts. However, the siren call of the market potentially distorts, obfuscates and dilutes their agentive potential as citizens within their basic and constructed roles as consumers. Finally, and perhaps one of the greatest challenges to this pedagogical project is the inactive citizenship displayed by many adults who operate within children's life worlds. 
It is the task, then, of education and curriculum in this scenario to continually confront the complexity and contradictions of children's commercial culture to assist in the ongoing project of shaping and sustaining lifelong ethical relationships with and between peoples, places, things, and thoughts. The role of teachers and curriculum in such a scenario is to continually awaken in students an awareness of the messages and values of the culture they consume and create and the responsibilities that now must be shared as we all continue to re-learn how to know, do, be, and live together. This confrontation, I think, is not as Reynolds (2004) suggests "continually tactical, not strategic" (p. 31) but must be both tactical and strategic.

Confronting and engaging this task is a difficult and important one. It necessitates a stance that is inclusive of both relentless activism and spontaneous reactivism, one that recognizes that "relationalism ... does not imply relativism" (Linell, p. 9, online). Such a stance requires radical openness in communicative practices. A dialogical approach such as that advanced by Linell (Online) and Renshaw and van der Linden (2004) provides a complementary perspective to that of complexity and is relevant to this discussion. Renshaw and van der Linden (2004) identify several features of a dialogic curriculum. These include that,

knowledge is viewed as constructed in interaction with others through dialogic processes of inquiry, exploration and mutual interrogation ... knowledge is linked necessarily to the formation and maintenance of communities .... A dialogical approach ... is respectful of the ideas, ways of speaking and cultures of students and their communities ... [it] engages students as collaborative knowledge-makers rather than consumers of knowledge ... [and] entails an ethic of answerability, built on a web of mutual obligations to be answerable to each other for our actions and for our silences. (pp. 30-31)

In attempting to harness the complexity of children's consumer culture in a pedagogical project that is desirous of crafting new ideas about citizenship and in which the polyphony of distant and diverse peoples, places, things and thoughts is potentially overwhelming, we must commit ourselves to engaging in, and fostering, the conditions for ongoing dialogical practices.

\section{Conclusion}

In Skerries of the Dream, a preface and critique of the graphic novel Volume Five the Sandman: A Game of You (Gaiman, 1993), Delany (1993) writes,

The Game of You, is after all, not the Game of I. (That's the "me-first" game-most of us know it only too well-where what I want is wholly above all other considerations and has to be pursued at any cost to anyone 
else.) ... no one can win the Game of I ... A Game of You is the only game worth playing - because it is the only game where, in the end, there's any hope of coming out ahead.

The curriculum of children's popular/ commercial culture where the Game of I is learnt and lived retains an emergent potential that can be leveraged by schools to foster a 'disposition to dialogue' vital to learning and living the Game of You.

What then might schools become in this scenario? The best answer I have received thus far to this question is simply, "something else." By attempting to harness complexity though we might hope for "something better."

\section{Acknowledgments}

I would like to thank Rebecca Luce-Kapler, Shalini Khan, Michelle Jordan and three anonymous reviewers for their helpful suggestions on earlier drafts of this paper. A shorter version of this paper was presented at the Third Complexity Science and Education Conference, Robert, LA, 2005.

\section{References}

Adler, P.A., \& Adler, P. 1998. Peer power: Preadolescent culture and identity. New Jersey: Rutgers University Press.

Anyon, J. 1980. Social class and the hidden curriculum of work. Journal of Education 162: 67-92.

Axelrod, R., \& Cohen, M.D. 1999. Harnessing complexity: Organizational implications of a scientific frontier. New York: The Free Press.

Binde, J. (Ed.) 2004. The future of values: 21 ${ }^{\text {st }}$ century talks. New York: UNESCO and Berghanan Books.

Binde, J. 2004a. The natural contract and development in the $21^{\text {st }}$ century. In J. Binde (Ed.), The future of values: $21^{\text {st }}$ century talks (pp. 198-203). New York: UNESCO and Berghanan Books.

Burch, K.T. 2000. Eros as the educational principle of democracy. New York: Peter Lang.

Cohen, S. 1972. Folk devils and moral panics: The creation of the mods and the rockers. London: MacKibbon and Kee.

Cook, D.T. 2001. Exchange value as pedagogy in children's leisure: Moral panics in children's culture at century's end. Leisure Sciences 23: 81-98.

Davis, B. 2004. Inventions of teaching: A genealogy. Mahwah, NJ: Lawrence Erlbaum Associates.

Davis, B., \& Simmt, E. 2003. Understanding learning systems: Mathematics education and complexity science. Journal for Research in Mathematics Education 34(2): 137167.

Delany, S.R. 1993. Skerries of the dream: A preface. In N. Gaiman (Writer). Volume five the Sandman: A game of You. New York: Vertigo, DC Comics. 
Delors, J. 2004. Towards lifelong education for all. In J. Binde (Ed.), The future of values: $21^{\text {st }}$ century talks (pp. 181-186). New York: UNESCO and Berghanan Books.

Delpit, L.D. 1988. The silenced dialogue: Power and pedagogy in educating other people's children. Harvard Educational Review 58(3): 280-298.

Deluze, G. 1995. Negotiations: 1972-1990. (M. Joughin, Trans.). New York: Columbia Press.

Eminem 2002. Square dance. On The Eminem Show [CD]. USA: Interscope Records.

Gaiman, N. 1993. Volume five the sandman: A game of You. New York: Vertigo, DC Comics.

Giroux, H.A. 2000. Stealing innocence: Youth corporate power and the politics of culture. New York: St. Martin's Press.

Hayes, M.T., \& Johnson, G.G. 2003. Popular music as embodied pedagogy. Journal of Curriculum Theorizing 19(3): 143-159.

Jelev, J. 2004. Education and citizenship in the twenty-first century. In J. Binde (Ed.), The future of values: $21^{\text {st }}$ century talks. (pp. 187-190). New York: UNESCO and Berghanan Books.

Kline, S. 1993. Out of the garden: Toys and children's culture in the age of TV marketing. London: Verso.

Ladson-Billings, G. 2005. Differing concepts of citizenship: Schools and communities as sites of civic development. In N. Noddings (Ed.), Educating citizens for global awareness (pp. 69-80). New York: Teachers College Press.

Langer, B. 2004. The business of branded enchantment: Ambivalence and disjuncture in the global children's culture industry. Journal of Consumer Culture 4(2): 251-277.

Linell, P. (n.d.). Essentials of dialogism: Aspects and elements of a dialogical approach to language, communication and cognition. Available at http://www.tema.liu.se/temak/personal/perli/Linell_Essentials-of-dialogism_050625.pdf

Linn, S. 2004. Consuming kids: The hostile takeover of childhood. New York: The New Press.

Martens, L., Southerton, M., \& Scott, S. 2004. Bringing children (and parents) into the sociology of consumption: Towards a theoretical and empirical agenda. Journal of Consumer Culture 4(2): 155-182.

Matsuura, K. 2004. Preface. In J. Binde (Ed.), The future of values: $21^{\text {st }}$ century talks. (pp. ix-x). New York: UNESCO and Berghanan Books.

Morin, E. 2004. Future ethics and politics. In J. Binde (Ed.), The future of values: $21^{\text {st }}$ century talks. (pp.241-244). New York: UNESCO and Berghanan Books.

Noddings, N. 2005. Global citizenship: Promises and problems. In N. Noddings (Ed.), Educating citizens for global awareness (pp. 1-21). New York: Teachers College Press.

O.Sullivan, E.V. 2002. The project and vision of transformative education: Integral transformative learning. In E.V. O'Sullivan, A. Morrell, \& M.A. O-Connor (Eds.), Expanding the boundaries of transformative learning: Essays on theory and praxis (pp. 1-12). New York: Palgrave.

Renshaw, P.D., \& van der Linden, J. 2004. Curriculum as dialogue. In J. Terwel \& D. Walker (Eds.), Curriculum as a shaping force: Toward a principled approach in curriculum theory and practice (pp. 17-32). New York: Nova.

Reynolds, W.M. 2004. To touch the clouds standing on top of a Maytag refrigerator: Brand-name postmodernity and a Deluzian "in-between". In W.M. Reynolds \& J.A. Webber (Eds.), Expanding curriculum theory: Dis/positions and lines of flight (pp. 19-33). Mahwah, NJ: Lawrence Erlbaum Associates. 
Salomon, G., \& Perkins, D.N. 1998. Individual and social aspects of learning. Review of Research in Education 23: 1-24.

Schor, J.B. 2004. Born to buy. New York: Scribner.

Sumara, D., \& Davis, B. 1999. Interrupting heteronormativity: Toward a queer curriculum theory. Curriculum Inquiry 29(2): 191-208.

Touraine, A. 2004. The case for a cultural contract. In J. Binde (Ed.). The future of values: $21^{\text {st }}$ century talks (pp. 217-219). New York: UNESCO and Berghanan Books.

Visser, J. 2001. Factors that lead to the evolution of a learning society. Learning Development Institute Working Paper \#2. Available at http:/ / www.learndev.org/ dl / FactorsThatFoster.pdf

Wachowski, L., \& Wachowski, A. (Writers/Directors). 1999. The Matrix [Motion Picture]. USA: Warner-Brothers.

\begin{abstract}
About the Author
Steven Khan is a Commonwealth Scholar from Trinidad \& Tobago where he taught High School Mathematics and Biology for five years. He is currently pursuing a Masters of Education at Queen's University in Kingston, Ontario with a focus on communication in mathematics classrooms though he has diverse interests in education. e-mail: stevepc@hotmail.com.
\end{abstract}

(C) Copyright 2006. The author, STEVEN KHAN, assigns to the University of Alberta and other educational and non-profit institutions a non-exclusive license to use this document for personal use and in courses of instruction provided that the article is used in full and this copyright statement is reproduced. The authors also grant a non-exclusive license to the University of Alberta to publish this document in full on the World Wide Web, and for the document to be published on mirrors on the World Wide Web. Any other usage is prohibited without the express permission of the author. 
